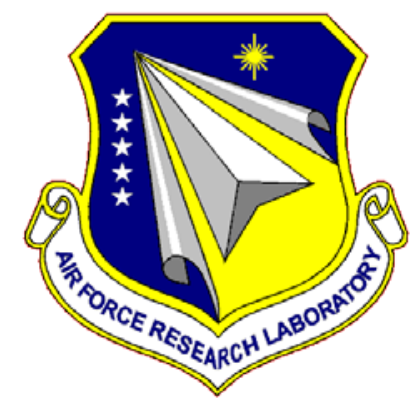

\title{
AFRL-RX-WP-TR-2014-0086
}

\section{INTEGRATED COMPUTATIONAL MODEL DEVELOPMENT}

Andrew Rosenberger

AFRL/RXCM

MARCH 2014

Final Report

\section{Approved for public release; distribution unlimited.} See additional restrictions described on inside pages

\section{STINFO COPY}

AIR FORCE RESEARCH LABORATORY

MATERIALS AND MANUFACTURING DIRECTORATE WRIGHT-PATTERSON AIR FORCE BASE, OH 45433-7750

AIR FORCE MATERIEL COMMAND UNITED STATES AIR FORCE 


\section{NOTICE AND SIGNATURE PAGE}

Using Government drawings, specifications, or other data included in this document for any purpose other than Government procurement does not in any way obligate the U.S. Government. The fact that the Government formulated or supplied the drawings, specifications, or other data does not license the holder or any other person or corporation; or convey any rights or permission to manufacture, use, or sell any patented invention that may relate to them.

This report was cleared for public release by the USAF 88th Air Base Wing (88 ABW) Public Affairs Office (PAO) and is available to the general public, including foreign nationals.

Copies may be obtained from the Defense Technical Information Center (DTIC) (http://www.dtic.mil).

AFRL-RX-WP-TR-2014-0086 HAS BEEN REVIEWED AND IS APPROVED FOR PUBLICATION IN ACCORDANCE WITH ASSIGNED DISTRIBUTION STATEMENT.

//Signature//

ANDREW ROSENBERGER, Project Engineer Metals Branch

Structural Materials Division
//Signature//

DANIEL EVANS, Chief

Metals Branch

Structural Materials Division

//Signature//

ROBERT T. MARSHALL, Deputy Chief

Structural Materials Division

Materials and Manufacturing Directorate

This report is published in the interest of scientific and technical information exchange, and its publication does not constitute the Government's approval or disapproval of its ideas or findings. 


\section{REPORT DOCUMENTATION PAGE}

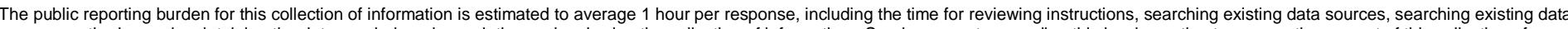

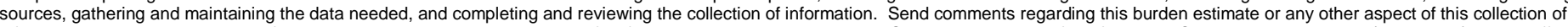

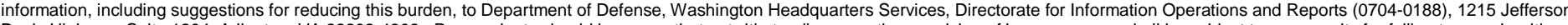

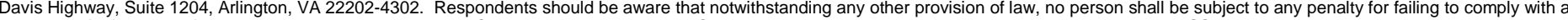
collection of information if it does not display a currently valid OMB control number. PLEASE DO NOT RETURN YOUR FORM TO THE ABOVE ADDRESS.
1. REPORT DATE (DD-MM-YY)
March 2014
2. REPORT TYPE
Final Report
4. TITLE AND SUBTITLE

INTEGRATED COMPUTATIONAL MODEL DEVELOPMENT

\section{AUTHOR(S)}

Andrew Rosenberger
3. DATES COVERED (From - To)

4 February 2009 - 28 February 2014

5a. CONTRACT NUMBER

In-house

5b. GRANT NUMBER

5c. PROGRAM ELEMENT NUMBER

$62102 \mathrm{~F}$

5d. PROJECT NUMBER

4347

5e. TASK NUMBER

5f. WORK UNIT NUMBER

X071

8. PERFORMING ORGANIZATION REPORT NUMBER

\section{AFRL/RXCM}

Bldg 654, RM 136

2941 Hobson Way

Wright Patterson Air Force Base, OH 45433-7750

9. SPONSORING/MONITORING AGENCY NAME(S) AND ADDRESS(ES)

Air Force Research Laboratory

Materials and Manufacturing Directorate

Wright-Patterson Air Force Base, OH 45433-7750

Air Force Materiel Command

United States Air Force

10. SPONSORING/MONITORING AGENCY ACRONYM(S)

AFRL/RXCM

11. SPONSORING/MONITORING AGENCY REPORT NUMBER(S)

AFRL-RX-WP-TR-2014-0086

\section{DISTRIBUTION/AVAILABILITY STATEMENT}

Approved for public release (PA); distribution unlimited.

13. SUPPLEMENTARY NOTES

PA Case Number: 88ABW-2014-1545; Clearance Date: 10 Apr 2014. This document contains color.

14. ABSTRACT (Maximum 200 words)

The Integrated Computational Model Development (ICMD) program worked to develop multiscale computational tools to predict material behavior based on its microstructure to: 1) accelerate materials development, 2) optimize the material and processes to ensure an optimal engineering design, and 3) enable optimized design using location-specific material properties.

\section{SUBJECT TERMS}

alloy design, microstructure, mechanical properties, fatigue behavior, crack growth behavior, image processing

\section{SECURITY CLASSIFICATION OF:}

a. REPORT

Unclassified
Unclassified b. ABSTRACT c. THIS PAGE

Unclassified

\begin{tabular}{c|c|}
$\begin{array}{c}\text { 17. LIMITATION } \\
\text { OF ABSTRACT: }\end{array}$ & $\begin{array}{c}\text { 18. NUMBER } \\
\text { OF PAGES }\end{array}$ \\
SAR & 13
\end{tabular}

19a. NAME OF RESPONSIBLE PERSON (Monitor)

Andrew Rosenberger

19b. TELEPHONE NUMBER (Include Area Code)

(937) 255-3304 


\section{Table of Contents}

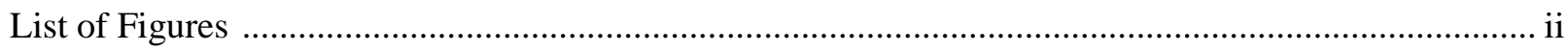

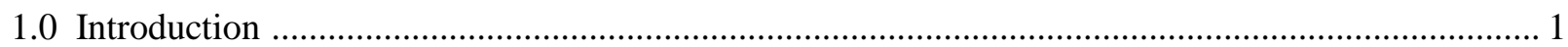

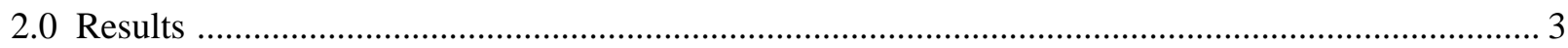

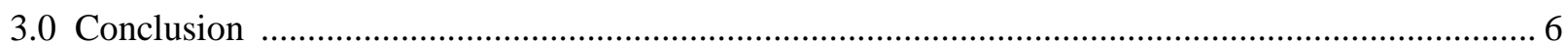

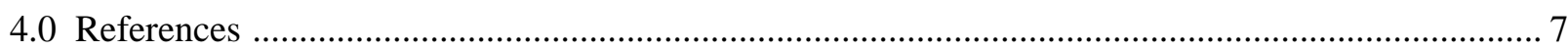

LIST OF ACRONYMS, ABBREVIATIONS AND SYMBOLS …................................................ 8 


\section{List of Figures}

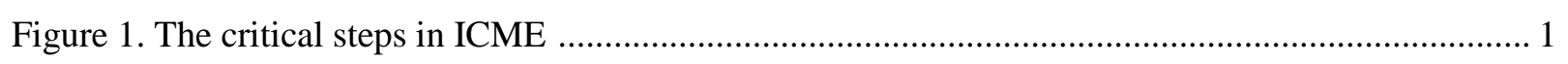




\subsection{Introduction}

The basis behind the ICMD Program is Integrated Computational Materials Engineering (ICME) [1]. ICME is "the integration of materials Information, captured in computational tools, with engineering product performance analysis and manufacturing-process simulation.” Essentially this is trying to put materials design and selection on the same computational footing as fluid design is with CFD and structural analysis is with FEA. Like these tools, the ICME needs to be integrated with the design process. A flow chart of ICME might look something like Figure 1 below.

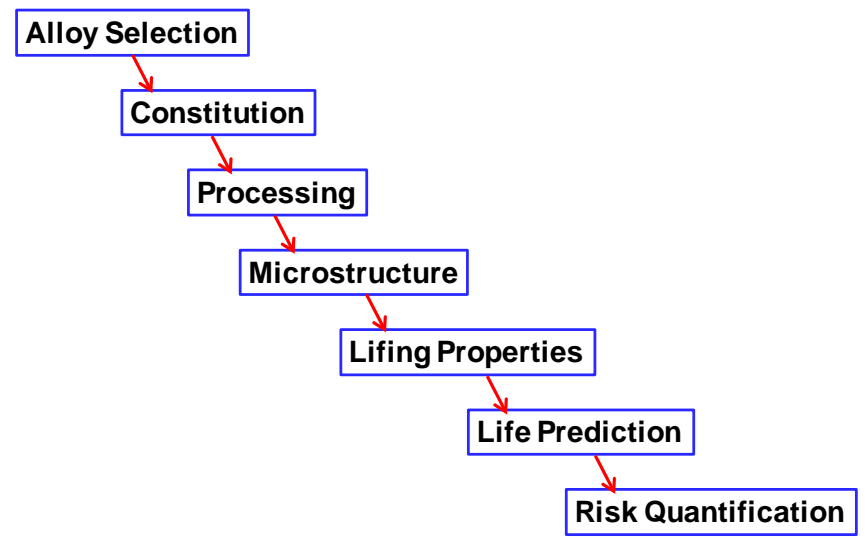

Figure 1. The critical steps in ICME

What this is not shown is the feedback that is necessary from each step to the previous step. If the component life is not sufficient, the microstructure, processing, constitution, or alloy might not be correct. A critical piece of ICME is the "integration." For years materials laboratories have been working the tools for ICME but have not integrated their produces or had a start to finish view of what they were doing and why.

The purpose of the Integrated Computational Model Development research was to develop computational models to ultimately predict the behavior of metallic materials from information on their composition and processing steps. That is, the ICMD program is working to integrate the steps in the middle of Figure 1 from "Constitution" to "Lifing Properties". Currently there is no computational basis for selecting a material or microstructure for a structural or functional application. Other computational tools exist; Finite Element Analysis for structural analysis, Computational Fluid Dynamics for fluid or aerodynamic analysis, but tools are needed for materials design and selection that will enable more rapid insertion of new materials and processes into fracture critical applications. The multiscale models that resulted from this research start to provide the ability to accelerate materials development, optimize the material and processes to ensure an optimal engineering design, and allow the design engineer to specify location specific material properties to further optimize the design.

The program objectives was to integrate computational materials science/engineering tools into a holistic system that could; 1) accelerate materials development, 2) transform engineering design/optimization processes, and 3) unify design and manufacturing. To start to achieve these goals, the program contained four task or thrust areas dealing with a) materials and processes (M\&P), b) the representation of material microstructures, c) computational models linking microstructure and mechanical performance, and d) novel experimental techniques. These four areas are explained in more detail below.

Approved for public release; distribution unlimited. 
- $\quad$ M \& P - Study approaches to incorporate the fundamental material constituents into current heat treat, deformation / processing and structural models. This includes, but is not limited to, alloy discovery and new approaches for attaining balanced materials properties for high temperature aerospace applications.

- Materials and microstructure representation - Develop tools and techniques for measuring multiscale 3-D microstructures and their representation as 3D volumes, descriptor representations and statistically equivalent synthetic microstructures that can be utilized by current and emerging computational techniques such as FEM-crystal plasticity.

- Computational Models - Develop computational tools and models that describe the material's mechanical behavior from the point of view of the material chemistry and microstructure. This can include but is not limited to, electronic structure, molecular dynamics, microstructural evolution methods, dislocation dynamics, scale-specific crystal plasticity, and mesoscale FEM / BEM. It is important to couple modeling regimes with experimental validation methods with the goal of coordinating material property models over the range of spatial and temporal scales.

- Experimental - Develop novel experimental techniques that characterize the material behavior at various length scales to elucidate the role of material constituents and their statistics on the resultant tensile, creep and fatigue behavior. This effort focuses on, but is not limited to, techniques and data that validate the computational models and offer insight into their development.

The program progress in these four areas is discussed in the following sections. 


\subsection{Results}

\section{Materials \& Processes}

The progress in materials and processes (M\&P) task was limited as the bulk of the program work was focused on existing, mature materials. However progress was made in 2 areas. Ab-initio calculations were made of molten material behavior as applied to the casting of Ni-based superalloys:

Convective instabilities responsible for misoriented grains (freckle defects) in directionally solidified turbine airfoils are produced by variations in liquid-metal density with composition and temperature across the solidification zone. Here fundamental properties of molten Ni-based alloys, required for modeling these instabilities, are calculated using ab initio molecular dynamics simulations. Previous calculations on elemental, binary and ternary alloys produced liquid-phase molar volumes $(\mathrm{V}(\mathrm{c}, \mathrm{T}))$ within $0.6-1.8 \%$ of available experimental data and demonstrated that the simulations cells of 500 atoms were sufficient to converge properties of interest. In this work density inversion, an increase in density with increasing temperature is assessed in model Ni-Al$\mathrm{W}$ and Rene-N4 alloys. Calculations are performed using a recently implemented constant pressure methodology (NPT) which enables efficient simulation of highly complex alloys. Density inversion ( 2\%) is found for the Ni-Al-W alloys for target compositions and temperatures consistent with 0 and 0.5 solid volume fractions in the melt. [2]

Alloy discovery work focused on a new refractory niobium alloy where the goal was a material that had higher temperature capabilities:

A new refractory alloy, Nb20Cr20Mo10Ta10Zr20Ti20, was produced by vacuum arc melting. To close shrinkage porosity, it was hot isostatically pressed (HIPd) at $\mathrm{T}=1723 \mathrm{~K}$ and $\mathrm{P}=207 \mathrm{MPa}$ for 3 hours. In both as-solidified and HIPd conditions, the alloy contained three phases: two body centered cubic (BCC1 and BCC2) and one face centered cubic (FCC). The BCC1 phase was slightly enriched with $\mathrm{Nb}$, Mo and Ta and depleted with $\mathrm{Zr}$ and $\mathrm{Cr}$, and its lattice parameter after HIP was a $=324.76 \pm 0.16 \mathrm{pm}$. The BCC2 phase was enriched with $\mathrm{Zr}$ and $\mathrm{Ti}$ and considerably depleted with Mo, $\mathrm{Cr}$ and Ta, and its lattice parameter after HIP was estimated to be a $=341.0 \pm$ $1.0 \mathrm{pm}$. The FCC phase was highly enriched with $\mathrm{Cr}$ and it was identified as a Laves C15 phase, $(\mathrm{Zr}, \mathrm{Ta})(\mathrm{Cr}, \mathrm{Mo}, \mathrm{Nb}) 2$, with the lattice parameter $\mathrm{a}=733.38 \pm 0.18 \mathrm{pm}$. The volume fractions of the BCC1, BCC2 and FCC phases were $68.5 \%, 9.6 \%$ and $21.9 \%$, respectively. The alloy density and Vickers microhardness were $\rho=8.23 \pm 0.01 \mathrm{~g} / \mathrm{cm} 3$ and $\mathrm{Hv}=5288 \pm 1 \mathrm{MPa}$. [3]

\section{Materials and Microstructure Representation}

Computational models that incorporate the specific characteristics of the material require accurate representations of the material and it's structure. Much progress was made in this area under the ICMD program using new tools (discussed later) and analytical techniques. One of the most promising developments is an automated method to extract the dendrite cores in a single crystal nickel-base superalloy casting:

Serial sectioning methods continue to produce a wealth of image data for quantifying the threedimensional nature of material microstructures. In this work, we discuss a computational methodology for automated detection and 3D characterization of dendrite cores from images taken from slices of a production turbine blade made of a heat-treated single crystal Ni-based superalloy. The dendrite core locations are detected using an automated segmentation technique that incorporates information over multiple length scales and exploits the four-fold symmetry of the dendrites when viewed down the $\{100\}$ growth direction. Additional rules that take advantage of the continuity of the dendrites from slice to slice help to exclude segmentation artifacts and 
improve dendrite core segmentation. The significance of this technique is that it may be extended to include any symmetric features. [4]

\section{Computational Models}

The M\&P and materials representation work will not impact the real world unless that information can be integrated in models that predict material performance. This area was advanced under the ICMD program wherein a new understanding of metal fatigue was developed and demonstrated for several materials. Two examples are shown here that apply to a titanium alloy and a nickel-base superalloy:

The effect of microstructural heterogeneity, specifically regions of grains with similar crystallographic orientations, or microtexture, on the initiation and early growth of fatigue cracks from multiple micro-notches has been investigated in Ti- 6246. Experiments were performed using ultrasonic fatigue techniques for two different microstructural conditions. Local texture surrounding micro-notches was found to influence micro-notch fatigue crack initiation in one of the microstructures. Fatigue crack initiation was least likely to occur from notches placed in neighborhoods with a microtexture unfavorably oriented for easy basal slip. However, small fatigue crack propagation rates were not influenced by the microtexture in these local neighborhoods. A systematic variation in micro-notch length indicated that fatigue cracks initiated from naturally occurring microstructural features when micro-notches with a surface length (2c) less than 15-20 $\mu \mathrm{m}$ were machined in specimens. [5]

IN100 is one of the workhorse nickel-base superalloys of the current fleet of turbine engines owned and operated by the US Air Force. Many of the life-limited locations on fracture critical IN100 components are associated with locations of stress concentrations, e.g. bolt holes, fillets, balance flange scallops, etc. The prior work by Jha, Caton, and others examining the fatigue variability of nickel-base superalloys found a link between the minimum fatigue life and fracture mechanics. This prior work only examined the fatigue behavior of smooth fatigue bars. The current effort determined that the link between minimum fatigue life and fracture mechanics is applicable even when only a small volume of the material at the root of a notch is subject to the high stress conditions. [6]

\section{Experimental}

Many new experimental techniques were developed in the ICMD program that will help to integrate materials science with the materials performance. Tools were developed that more rapidly characterize the material microstructure in 2- and 3-D. Techniques to mechanically test materials at smaller scales were developed to better inform the deformation models. Also methods were developed to characterize the growth of microstructurally small cracks under various loading conditions.

This article presents a brief overview of current instruments for collection of microstructural data sets in three dimensions (3D) via serial sectioning. These instruments are dedicated or adapted to the task of collecting serial section data, which greatly accelerate the characterization process, and in selected systems offer the ability incorporate multi-modal data, viz. combinations of images, crystallographic and chemical maps that enable robust and automated approaches to segmentation of grains and phases. [7]

Under high cycle and very high cycle fatigue (HCF and VHCF) conditions, scatter in fatigue lifetimes is substantial; often 2-3 orders of magnitude. Characterization of fatigue crack initiation sites in laboratory scale fatigue specimens has led to the identification of characteristic initiation sites and microstructural arrangements. Despite these observations, in some cases, it is still unclear how apparently similar initiation sites exhibit such different total fatigue lifetimes. Differences in crack-initiation mechanisms can be further revealed if specific microstructural 
arrangements are isolated to a micro-specimen. Towards this end, an in-situ microscale tension testing technique was adapted to enable microscale fatigue testing on tensile dog-bone specimens. Microscale tensile fatigue specimens with approximate gage diameters of 20 micrometers were prepared with a focused ion beam (FIB) microscope. Initial tensile experiments were conducted to characterize the mechanical behavior of microscale specimens for this microstructure. The microscale tensile specimens were observed to exhibit poorer mechanical properties than bulk tensile specimens. [8]

It has been observed that the life limiting fatigue behavior in numerous superalloys is dominated by small crack growth behavior. While environmental effects on crack growth behavior of Nibase superalloys are well documented within the literature, the published research is largely limited to long crack behavior due to the difficulty of measuring small cracks in a vacuum chamber. A testing capability for optical measurement of small cracks under ultra-high vacuum and at elevated temperatures has been developed. Optical measurement capabilities have been evaluated on a lab air machine to determine crack measurement accuracy. Vacuum tests were then run at $650{ }^{\circ} \mathrm{C}$ on Ni-base specimens to quantify the effect of vacuum on the propagation life within the small crack regime. The effectiveness of this test capability and considerations for this technique are discussed. [9] 


\subsection{Conclusion}

ICME is "the integration of materials Information, captured in computational tools, with engineering product performance analysis and manufacturing-process simulation.” [1] Essentially this is trying to put materials design and selection on the same computational footing as fluid design is with CFD and structural analysis is with FEA. Like these tools, the ICME needs to be integrated with the design process. The integrated computational Model Development program was the first attempt at accomplishing this. Progress was made, but integration is still required. Cleary this more than the Air Force can accomplish so the next steps include the development of program goals that include produce definition. This will help to focus the activity and build a stronger integrated activity. 


\subsection{References}

[1] Integrated Computational Materials Engineering, National Materials Advisory Board of the National Research Council, National Academies Press, Washington, DC, 2008.

[2] Christopher Woodward and James Lill, "Ab-inito Molecular Dynamics Simulations of Molten NiBased Superalloys,” AFRL-RX-WP-TP-2011-4370, Wright-Patterson AFB, OH, October 2011.

[3] O.N. Senkov and C.F. Woodward, "Microstructure and Properties of a Refractory NbCrMo0.5Ta0.5ZrTi Alloy,” AFRL-RX-WP-TP-2011-4372, Wright-Patterson AFB, OH, October 2011

[4] M.A. Tschopp, M.A. Groeber, J.P. Simmons, A.H. Rosenberger, and C. Woodward, “Technique for Automated Extraction of Symmetric Microstructural Features: Application to Dendritic Cores in Single Crystal Ni-Based Superalloys,” AFRL-RX-WP-TP-2011-4115, Wright-Patterson AFB, OH, March 2011

[5] C. J. Szczepanski, S. K. Jha, J. M. Larsen, and J. W. Jones, "The Role of Microtexture on the Fatigue Behavior of an $\alpha+\beta$ Titanium Alloy, Ti-6Al-2Sn-4Zr-6Mo,” AFRL-RX-WP-TP-2011-4208, WrightPatterson AFB, OH, March 2011

[6] Andrew H. Rosenberger, Dennis J. Buchanan, D’Anthony A. Ward, and Sushant K. Jha, “The Variability of Fatigue in Notched Bars of IN100,” AFRL-RX-WP-TP-2012-0388, Wright-Patterson AFB, $\mathrm{OH}$, August 2012

[7] Michael D. Uchic, Michael A. Groeber, and Anthony D. Rollett, “Automated Serial Sectioning Methods for Rapid Collection of 3D Microstructure Data,” AFRL-RX-WP-TP-2011-4211, WrightPatterson AFB, OH, March 2011

[8] C.J. Szczepanski, S.K. Jha, P.A. Shade, R. Wheeler, J.M. Larsen, "Adaptation of an in-situ Microscale Tension Technique to Enable Fatigue Testing,” AFRL-RX-WP-TP-2012-0386, Wright-Patterson AFB, $\mathrm{OH}$, August 2012

[9] B. T. Gockel, M. J. Caton, S. K. Jha, C. J. Szczepanski, and A. H. Rosenberger, “Developing the Capability to Monitor Small Fatigue Crack Growth under Elevated Temperature, Ultra-High Vacuum Conditions,” AFRL-RX-WP-TP-2011-4236, Wright-Patterson AFB, OH, July 2011 


\section{LIST OF ACRONYMS, ABBREVIATIONS AND SYMBOLS}

3D three dimensional

BCC body centered cubic

BEM boundary element method

CFD computational fluid dynamics

FCC face centered cubic

FEA finite element analysis

FEM finite element method

FIB focused ion beam

HCF high cycle fatigue

HIPd hot isostatically pressed

ICMD integrated computational model development

ICME integrated computational materials engineering

M\&P materials \& processes

NPT fixed-number, pressure and temperature

VHCF very high cycle fatigue 